\title{
Sediment management in tidal river: A case study of East Beel Khuksia, Bangladesh
}

\author{
Rocky Talchabhadel ${ }^{1, *}$, Hajime Nakagawa ${ }^{1}$, and Kenji Kawaike ${ }^{1}$ \\ ${ }^{1}$ Disaster Prevention Research Institute, Kyoto University, Japan
}

\begin{abstract}
The widespread construction of coastal embankments limited the natural deposition on the floodplain and accelerated the silt deposition in river channels. It resulted in drainage congestion and large-scale waterlogging problem. The temporary de-poldering is one of the effective methods to solve this issue. During high tide, muddy water enters the selected tidal basin depositing a major portion of sediment and at low tide, relatively clearer water erodes the riverbed. This paper presents a twodimensional numerical model to simulate the mechanism of sediment transport and deposition during the process of controlled flooding. The model was applied to three different scenarios of the embankment cuts in East beel Khuksia, Bangladesh. The study recommends operating single embankment cut at a time if the tidal equilibrium is fulfilled by the opening size of that embankment cut. The developed model can be used to assess the land heightening in sediment-starved tidal basins and ultimately plan the rotation of tidal basins for sustainable sediment management.
\end{abstract}

\section{Introduction}

The southwest (SW) coastal part of Bangladesh shown in Fig. $\mathbf{1}$ has been suffering badly from river sedimentation and drainage congestion over the last few decades. The series of polders were built into encircled embankments around beels (a Bengali term used for large depressions that accumulate water) in the 1960s and 1970s to protect flood and grow more crops. People initially benefitted, however, the adverse effects were enormous. The embankments restricted the gradual process of silt deposition in beels that helps maintain an elevation of the landscape. At the same time, they led to accelerated silt deposition in the rivers resulting riverbed higher than floodplains. Several tidal channels died within a few years to few decades. As the water from those beels could neither be drained away overland nor could it be discharged, the severe drainage congestion and waterlogging affect the homesteads and livelihood activities [1].

\subsection{From Polder to De-polder}

The controlled breaching of embankments (de-poldering) can restore the elevation of the sediment-starved beels. The centrepiece of debate on poldering and de-poldering started with a public Embankment Cut (EC) in beel Dakatia. In September 1990, during a mass

*Corresponding author: rocky@uh31.dpri.kyoto-u.ac.jp 
community mobilization (mahashamabesh), four non-authorized breaches were made by the public in the embankment with the intention of draining away water from the beel. Although a large quantity of water flowed through it, the cuts caused salinity intrusion which caused crop destruction and human suffering. In 1994, Bangladesh Water Development Board (BWDB) closed the cuts. The temporary de-poldering for solving drainage congestion came to be known conceptually as Tidal River Management (TRM). Although there were some plans for controlled tidal flooding, BWDB did not include the practice.

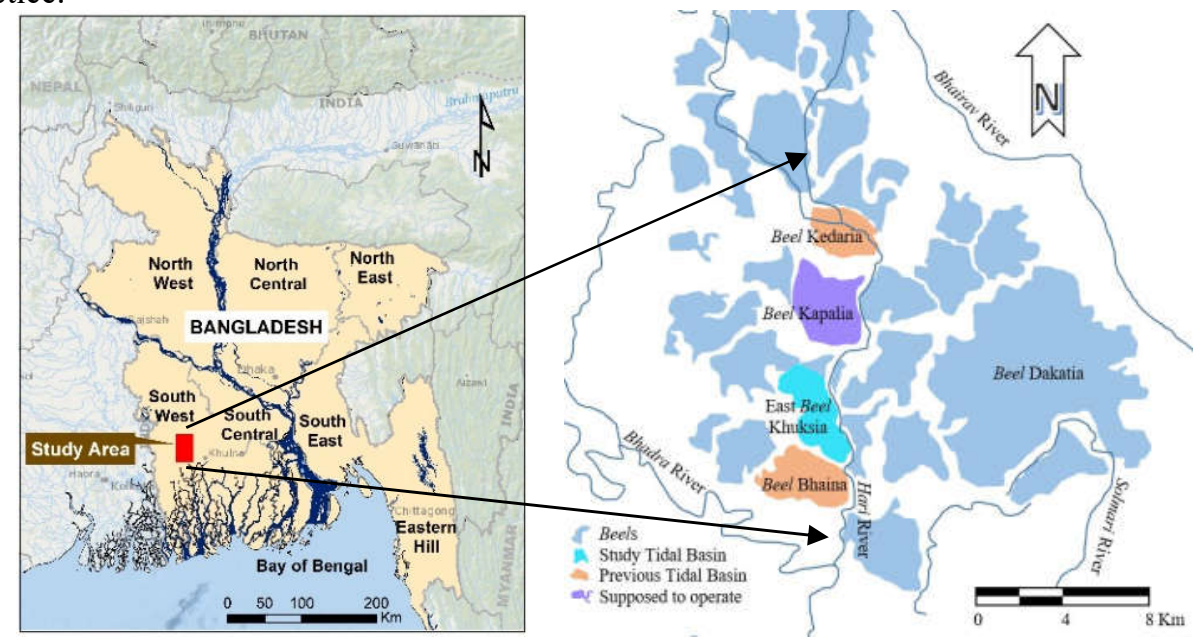

Fig. 1. Hydrological region of Bangladesh (North West, North Central, North East, South West, South Central, South East and Eastern Hill) and location of beels in Hari River

The additional effects of the devastating flood in the year 1998 was added which created the worse scenario of prolonged stagnant waterlogging. Similar to beel Dakatia, local people had cut the sections of the embankment at beel Bhaina [2]. After de-poldering, rapid drainage and recession of water took place because of a high magnitude of head difference. After few days, the tide started to enter into the beel from the de-poldered section as a natural phenomenon to create tidal flooding. The natural tidal flow formed a wider channel that was beyond the capacity of the local people to close it. At the end of the dry season, the local people surprisingly noticed that the land level of beel Bhaina had been raised and the depth of Hari River had been increased significantly.

\subsection{From TRM to TBM}

The local people became interested in this process and urged the BWDB to apply the process sequentially in all the beels. De-poldering and controlled flooding in a particular area is not a new way of sediment management. But, here it involves taking full advantages of the natural tide movement in rivers [3,4]. Tidal basin acts as sedimentation trap to allow silt deposition and natural tidal flows up and down in the river system. The natural flow as low tide going back to the river benefits in the river declination. The system is effective to heighten land for cultivation, improve the navigability of the tidal river, mitigate the waterlogging crisis, and revive the river functionality. When one tidal basin has achieved the designated land heightening, then another tidal basin takes the sediment load. Various beels are rotated within the system so that landowners/farmers of one do not have to suffer for a long time, the process is Tidal Basin Management (TBM). A proposed TBM in Hari river system is shown in Table 1. 
Table 1. The proposed plan of TBM in the Hari River [5]

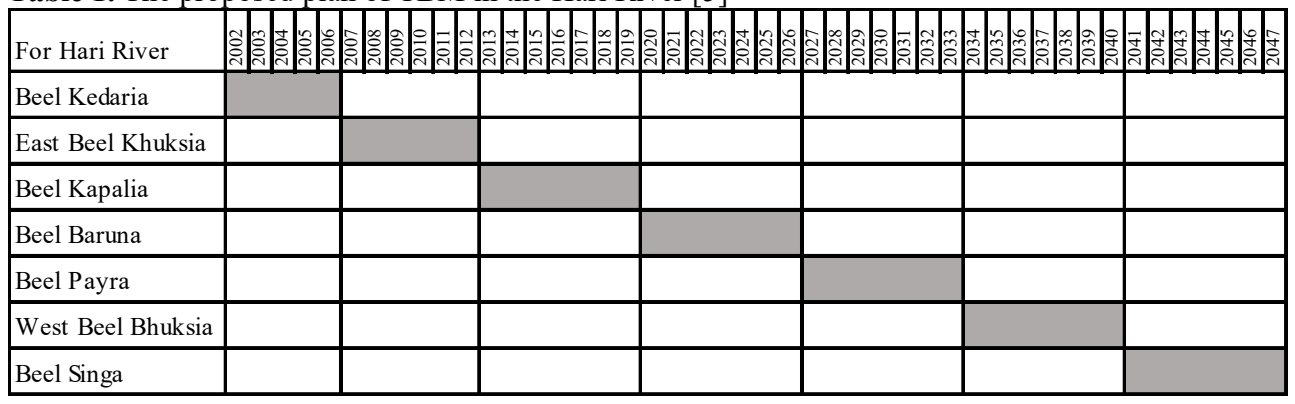

\subsection{Objectives of the study}

Most of the literature reviews reveal that a number of comprehensive studies on TRM/TBM are available. These studies cover a wide range of analysis regarding appropriate planning, design, and implementation of TBM in a coastal river [6]. They have discussed the implications of TBM on disaster management [7,8], livelihood [9], ecosystem and environment. Some of the researchers have discussed regarding the mainstreaming of TBM for participatory environmental governance [10], flood policy [11,12], climate change adaptation [13], drainage rehabilitation project [14] and suggested the conceptual framework $[15,16]$ for sustainability. Very limited researchers [2-4,17] have attempted to numerically simulate the process of TBM. Some of the experiences of TBM in Bangladesh either proved an unsuccessful outcome or far beyond the expectation resulting in the discouragement among local people to participate by giving their land.

Even the process has been one of the integral parts of sediment management for the tidal rivers in Bangladesh, very few studies are realized based on the numerical simulations and almost nil is found based on the experimental studies. In this context, attempts have been made to assess the effectiveness of the system through experimental and numerical simulation. To inspect the effectiveness of the TBM process exploring the different opening sizes and to compare with available empirical relations, the experimental setup was arranged considering a simplified version of TBM and was simulated numerically. See $[18,19]$ for a detailed explanation. The developed model validated in experimental domain here is attempted to apply in the actual case. Among three operated TBM in Hari river system, East Beel Khuksia (EBK) is taken as the case study for the application of the developed model. The main objective of the study is to assess the mechanism of sediment transport during TBM so that the developed numerical model can be used as a decisionmaking tool for effective sediment management.

\section{Study Area}

The study area is located in the SW coastal part of Bangladesh. The SW Bangladesh generally comprises districts of Satkhira, Khulna, Bagerghat, the southern part of Jessore and sometimes Narail. There are 67 beels in the SW Bangladesh [20]. The general characteristics of the region are: 1) tidal floodplain land, soil, and water are more saline, 2) very close to the sea (i.e. Bay of Bengal) and 3) very lower means sea level. The brackish water ecosystem brings large concentrations of sediment from the sea into the river system during high tides. Before polderization, major parts of incoming sediment deposited naturally on the beels that helped maintain the elevation. The sediment-starved area has been suffering badly from river sedimentation and drainage congestion over the last few decades. 
The location of the beels in Hari River system is shown in Fig. 1. EBK is taken as the case study for the application of the developed model. The operation of TBM in EBK was started in April 2006, but was closed by local villagers on July 15th, 2006. The EC was again opened on November 30th, 2006 [21]. Although, in the beginning, people of EBK did not want to operate TBM in their beel as they saw the unsuccessful result of beel Kedaria but later on they agreed. To distribute the sediment deposition more equally, a second EC was made $2.9 \mathrm{~km}$ upstream of the first EC around the monsoon period of 2007. A crossdam was constructed upstream of EC. It was supposed to operate for three years and close in 2009. But due to many unavoidable reasons, the proposed tidal basin in beel Kapalia did not start in 2009, as proposed. In December 2010, the first EC was closed and in February 2013, the second EC was closed.

\section{Numerical Simulation Model}

The flood simulation model used is a two-dimensional (2D) unsteady flow model by the finite difference method based on a shallow water equation.

\section{Continuity equation}

$$
\frac{\partial h}{\partial t}+\frac{\partial M}{\partial x}+\frac{\partial N}{\partial y}=0
$$

\section{Momentum equation}

$$
\begin{aligned}
& \frac{\partial M}{\partial t}+\frac{\partial(u M)}{\partial x}+\frac{\partial(u M)}{\partial y}=-g h \frac{\partial H}{\partial x}-\frac{g n^{2} u \sqrt{u^{2}+v^{2}}}{h^{1 / 3}} \\
& \frac{\partial N}{\partial t}+\frac{\partial(u N)}{\partial x}+\frac{\partial(v N)}{\partial y}=-g h \frac{\partial H}{\partial y}-\frac{g n^{2} v \sqrt{u^{2}+v^{2}}}{h^{1 / 3}}
\end{aligned}
$$

where, $h$ is the water depth (m), $M(=u h)$ and $N(=v h)$ are fluxes in the $x$ and $y$ directions, $u$ and $v$ are velocities in the $x$ and $y$ directions, $H$ is the water level, $g$ is the acceleration of gravity, and $n$ is the Manning's roughness coefficient.

\section{Suspended sediment transport calculation}

$$
\frac{\partial(C h)}{\partial t}+\frac{\partial(C M)}{\partial x}+\frac{\partial(C N)}{\partial y}=D\left(\frac{\partial^{2}(C h)}{\partial x^{2}}+\frac{\partial^{2}(C h)}{\partial y^{2}}\right)+E+C w
$$

where $C$ is the concentration of sediment, $D$ is a coefficient of diffusion, $E$ is the parameter of flowing up and $w$ is the settling velocity. Given the situation, $D$ is set to 0.1 $\mathrm{m}^{2} / \mathrm{s}$. In this study, the settling velocity is calculated with the Rubey's formula [22].

$$
w=\sqrt{\frac{2}{3}\left(\frac{\sigma}{\rho}-1\right) g d+\frac{36 v^{2}}{d^{2}}}-\frac{6 v}{d}
$$

where $\sigma$ is the density of sediment particles, $\rho$ is the water density, $d$ is the diameter of sediment particles and $v$ is the coefficient of kinematic viscosity of water. The upward flux is assumed to be under equilibrium condition. The equilibrium concentration is calculated using the van Rijn empirical formula [23].

$$
\begin{aligned}
& E=w C^{*} \\
& C^{*}=0.015 \frac{d T^{1.5}}{a D_{*}{ }^{0.3}}
\end{aligned}
$$

where $a$ is the reference is level taken $0.05 h, D_{*}$ is the particle size parameter and $T$ is a dimensionless excess bed shear stress parameter. $D_{*}$ and $T$ are defined by the equation 8 and 9 .

$$
D_{*}=d\left[\frac{\left(\frac{\sigma}{\rho}-1\right) g}{v^{2}}\right]^{1 / 3}
$$




$$
T=\frac{\tau_{*}-\tau_{*_{c}}}{\tau_{*_{c}}}
$$

where $\tau_{*}$ and $\tau_{*_{c}}$ are the dimensionless shear stress and critical shear stress according to the Shields. The grain related shear stress parameter $\tau_{*}$ is calculated by considering Chezy's equation.

$$
\begin{aligned}
\tau_{*} & =\frac{u_{*}{ }^{2}}{\left(\frac{\sigma}{\rho}-1\right) g d} \\
u_{*} & =\sqrt{g} \frac{u}{C^{\prime}}
\end{aligned}
$$

where $C^{\prime}=$ grain related Chezy's roughness coefficient which is given by :

$$
C^{\prime}=18 \log \left(\frac{12 h}{k_{s}}\right)
$$

where $k_{s}=$ grain roughness $=2.5 d_{50}$ which is used in the present study. The dimensionless critical shear stress $\tau_{*_{c}}$ for the sediment size $d$ is evaluated with the Iwagaki formula [24].

where

$$
\tau_{*_{c}}=\left\{\begin{array}{lr}
0.05 & \text { if } R_{*} \geq 671.0 \\
0.00849 R_{*}{ }^{3 / 11} & \text { if } 162.7 \leq R_{*}<671.0 \\
0.034 & \text { if } 54.2 \leq R_{*}<162.7 \\
0.195 R_{*}{ }^{-7 / 16} & \text { if } 2.14 \leq R_{*}<54.2 \\
0.14 & \text { if } R_{*}<2.14
\end{array}\right.
$$

$$
R_{*}=\frac{\sqrt{\left(\frac{\sigma}{\rho}-1\right) g d^{3}}}{v}
$$

The model has been checked and validated with experimental results (see [18,19] for detailed explanation). For the complicated and complex topography, the unstructured mesh has an advantage of flexibility over the structured mesh. Moreover, unstructured grids are identified by the irregular connectivity so that the sizes of the computational meshes could be easily varied from one area to other as per the needs. Computation meshes are unstructured and triangular in shape $[25,26]$. The leap-frog method is used to calculate the water depth and the flux.

The ground is divided by a non-structure mesh using the GID software. Digital Elevation Model (DEM) of $5 \mathrm{~m} \mathrm{X} 5 \mathrm{~m}$ resoultion isa derived from the bathymetric data of March 2007 provided by Institute of Water Modeling (IWM) is used to generate the mesh elevation data, as shown in Fig. 2. The size of the computation mesh is not uniform. The smaller mesh is specified in the river system, channels in the beels and connecting canals as shown in Fig. 2. The total mesh number is 11053 . The meshes at river system, channels, and connecting canals are given 0.025 Manning roughness coefficient whereas 0.04 for the remaining.
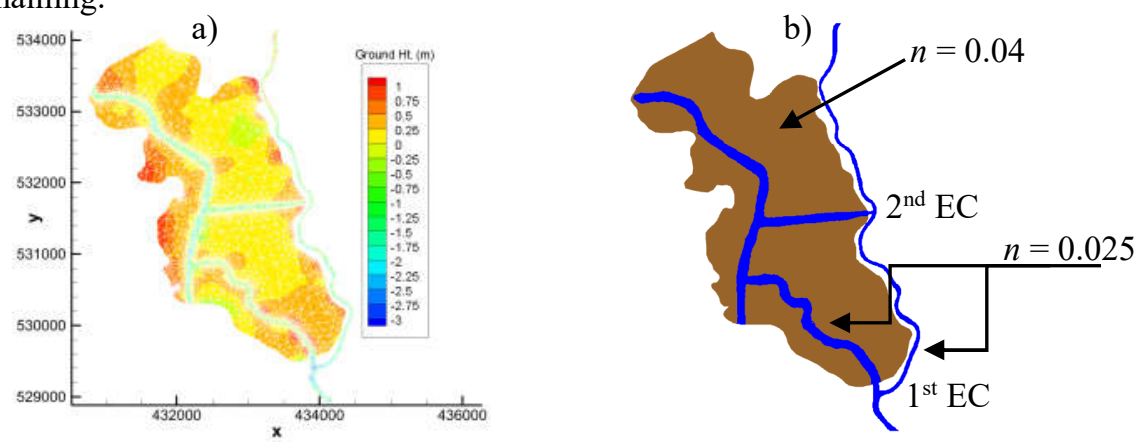

Fig. 2. a) Ground elevations and unstructured triangular meshes in the study tidal basin and b) adopted Manning roughness coefficient $(n)$ in computational domain 
a)

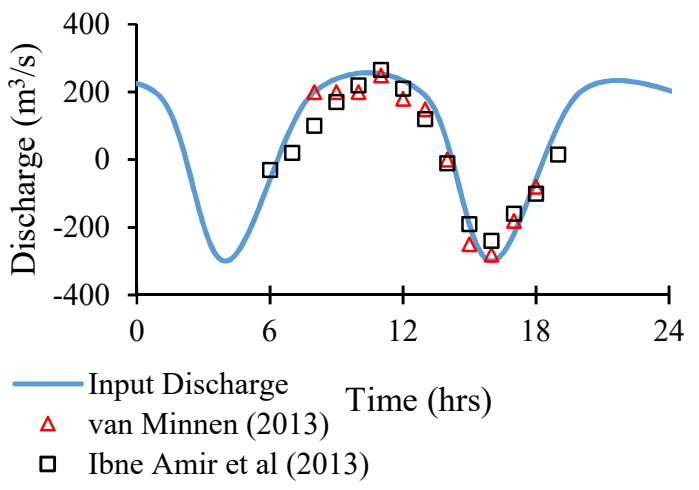

b)

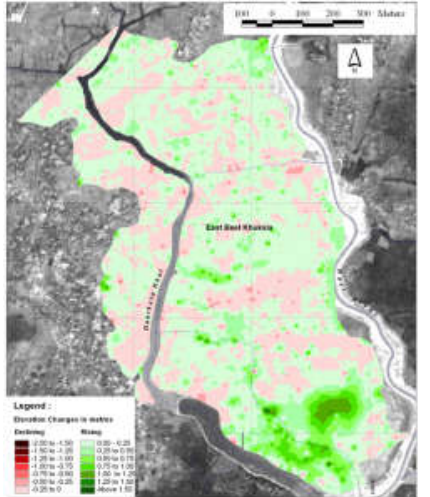

Fig. 3. a) Tidal discharge boundary condition for the simulation and b) Rate of sedimentation on EBK up to May 2007 [1] for validation

The river is covered with the fine sediment, or mud, originating from the Bay of Bengal. The grain size distribution done by Ibne Amir (2010) for the Hari River at Ranai from the measured bed sample was found to be $d_{50}=0.017 \mathrm{~mm}$ and $d_{90}=0.050 \mathrm{~mm}$. The mean size diameter of the sediment $0.025 \mathrm{~mm}$ (slightly greater than $d_{50}=0.017$ measured by Ibne Amir (2010) and congruous with some field-based data of $\left.d_{50}\right)$ is taken in the simulation. Since there is lack of long-term time series data of flow discharge and sediment concentration, the average of the some of the measured discharge [4,21] have been used in the simulation as repetitive condition [shown in Fig. 3 a)]. Similarly, the average of some of the measured SSCs $[4,21]$ (i.e. $900 \mathrm{gm} / \mathrm{m}^{3}$ ) is supplied during every high tide.

The rate of the sedimentation observed after the first six months of operation of TBM [shown in Fig. 3 b)] has been used to check the validity of the model. Van Minnen (2013) measured the sediment depth at few locations (shown in Fig. 4) adjacent to $2^{\text {nd }}$ EC during his field-work in November 2012. At that time $2^{\text {nd }}$ EC was operational and $1^{\text {st }} E C$ was already closed in December 2010. Table 2 shows the sediment deposition up to November 2012 at those locations (see [21] for detailed explanation). The real storyline case of the operation of EBK has been simulated (i.e. operation of the $1^{\text {st }} \mathrm{EC}$, then operation of the $2^{\text {nd }}$ $\mathrm{EC}$, closure of the $1^{\text {st }} \mathrm{EC}$ and finally closing the $2^{\text {nd }} \mathrm{EC}$ ). Above mentioned data (Table 2) are used to verify the applicability of the numerical model. After that, the effectiveness of the TBM system with different other options is assessed.
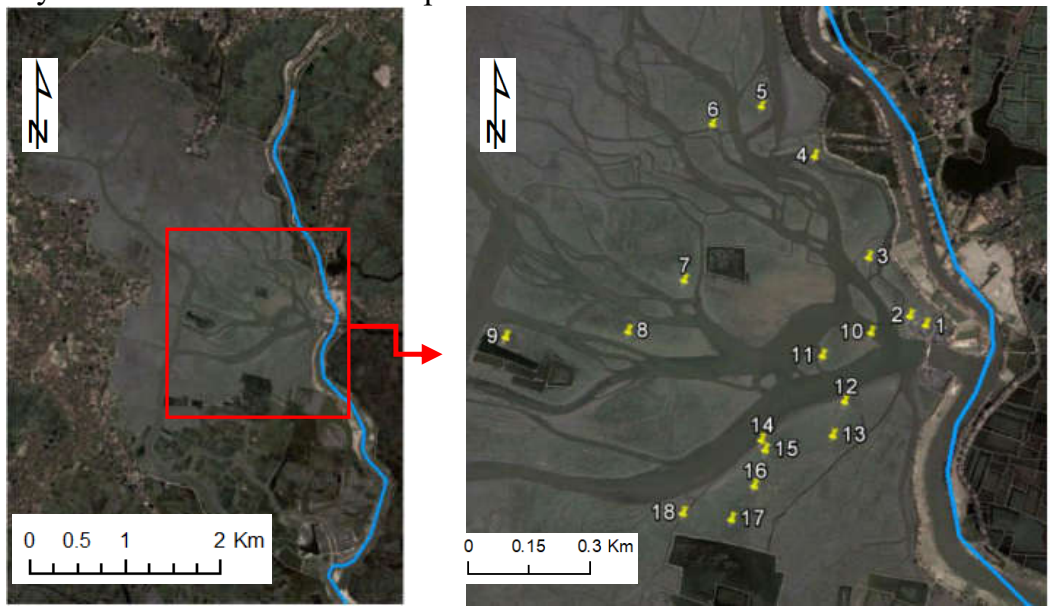

Fig. 4. Sediment depth point around second EC of EBK [21] 
Table 2. Sediment depths in November 2012 at sampling points [21]

\begin{tabular}{|r|r|r|r|r|r|}
\hline \multicolumn{1}{|c|}{ Point } & Depth (m) & Point & Depth (m) & Point & Depth (m) \\
\hline 1 & 1.7 & 7 & 2.2 & 13 & 3 \\
\hline 2 & 1.8 & 8 & 2.5 & 14 & 1.4 \\
\hline 3 & 2.2 & 9 & 2.1 & 15 & 1.4 \\
\hline 4 & 2 & 10 & 2.2 & 16 & 1.4 \\
\hline 5 & 2 & 11 & 2.2 & 17 & 1 \\
\hline 6 & 1.9 & 12 & 2 & 18 & 1.4 \\
\hline
\end{tabular}

Shampa and Pramanik (2012) has highlighted the importance of the crossing dam during the operation of TBM and also mentioned during the drier period, the significant deposition is acquired. The simulation is carried out for the the drier periods only (6 months in a year) for five years with the availability of crossing dam at upstream for three different cases:

1) $1^{\text {st }}$ EC only

2) Both ECs simultaneously and

3) $2^{\text {nd }}$ EC only.

\section{Results and discussions}

\subsection{Model Verification}

The developed numerical model was simulated with only $1^{\text {st }} \mathrm{EC}$ for first 6 months (i.e. the simulation of Dec 2006 - May 2007). The net sediment deposition is shown in Fig. 5 a). Similarly, to represent the time after the closing of the $1^{\text {st }} \mathrm{EC}$ and continuation of $2^{\text {nd }} \mathrm{EC}$, it was simulated for 2 years (i.e. the simulation of Dec 2010 - Nov 2012). The net sediment deposition during that period is shown in Fig. 5 b). The spatial distribution of the deposition for the simulation of Dec 2006 - May 2007 is compared with Fig. 3 b). Somewhere, the simulation has overestimated near the EC but the evolution of the deposition towards the tidal basin is congruous with the observed data. Similarly, the net deposition during the simulation of Dec 2010 - Nov 2012 is compared with the measured data shown in Table 2 at the locations shown in Fig. 4. The model has overestimated the deposition around the EC whereas underestimated the deposition far from the EC. The spatial distribution shows agreeable congruity with the results of Ibne Amir (2010). Within this validity, different cases have been analysed.
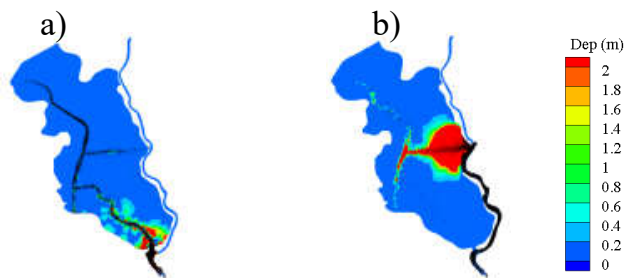

Fig. 5. Net deposition of the sediment for validation [a) after 6 months of the $1^{\text {st }}$ EC (Dec 2006 - May 2007), and b) after 2 years of the $2^{\text {nd }}$ EC (Dec 2010 - Nov 2012)]

\subsection{Assessment of different three cases}

The deposition of sediment progresses with the evolution of the time, most of the deposition happens near the EC (simulation result of Case 1 is shown in Fig. 6). In the actual case, when it was found land heightening could not happen in the northern side of EBK, $2^{\text {nd }} \mathrm{EC}$ was made from next drier season (i.e. 2007 onwards). When both the ECs are 
operational simultaneously (in Case 2), the tidal influence in $2^{\text {nd }} \mathrm{EC}$ is greatly reduced. Ogawa and Sawai (2013) has highlighted the effect of the remoteness of the inlet from the tidal source [28]. But in Case 3, due to the closure of $1^{\text {st }} \mathrm{EC}$, the tidal influence in $2^{\text {nd }} \mathrm{EC}$ is higher compared to Case 2. In any case, the northernmost part of the basin has not been utilized with both ECs which was verified by the field-based report of Van Minnen (2013). It can be inferred that the tidal basin size should be limited depending upon the tidal prism. To effectively utilize the spacious area of the EBK, one option could be an installation of the $3^{\text {rd }} \mathrm{EC}$ at more upstream than the $2^{\text {nd }} \mathrm{EC}$ and then closure of both $1^{\text {st }}$ and $2^{\text {nd }} \mathrm{ECs}$.
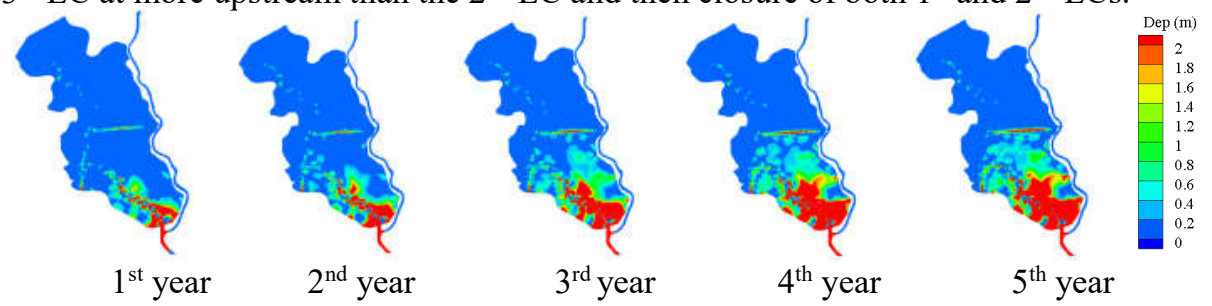

Fig. 6. Predicted net deposition pattern inside the tidal basin for case 1

The net deposition volume with the deposited area for case 1 is shown in Fig. 7 a). The rate of the increase of the sediment after 3 years is reduced significantly. The deposited area for four different levels (i.e. depth $>0.5 \mathrm{~m}, 1 \mathrm{~m}, 1.5 \mathrm{~m}$, and $2 \mathrm{~m}$ ) are also shown in Fig. 7 a). If the deposited sediment around the entrance of the EC is manually dredged or excavated, the efficacy of the process may be increased. Similar results have been observed for $2^{\text {nd }} E C$ (not shown). The net deposition of three different scenarios is shown in Fig. 7 b). Since the $2^{\text {nd }} \mathrm{EC}$ has lesser tidal influence than $1^{\text {st }} \mathrm{EC}$, the net deposition is greatly reduced. In the case of simultaneous operation of both the ECs, the total deposition is not so much significantly increased than the single operational case. It suggests that if the opening size of the EC is sufficient to maintain tidal equilibrium then the operation of single EC gives better results than multiple operations of ECs simultaneously. The opening size of EC can be determined by using consistent relationship between cross-section area and the tidal prism [29-32]. Additionally, compartmentalization and channelization can be applied for proper distribution of sediment in the selected EC. To have an additional benefit, manual/dredging around the entrance of EC could be done along with natural tidal movement.
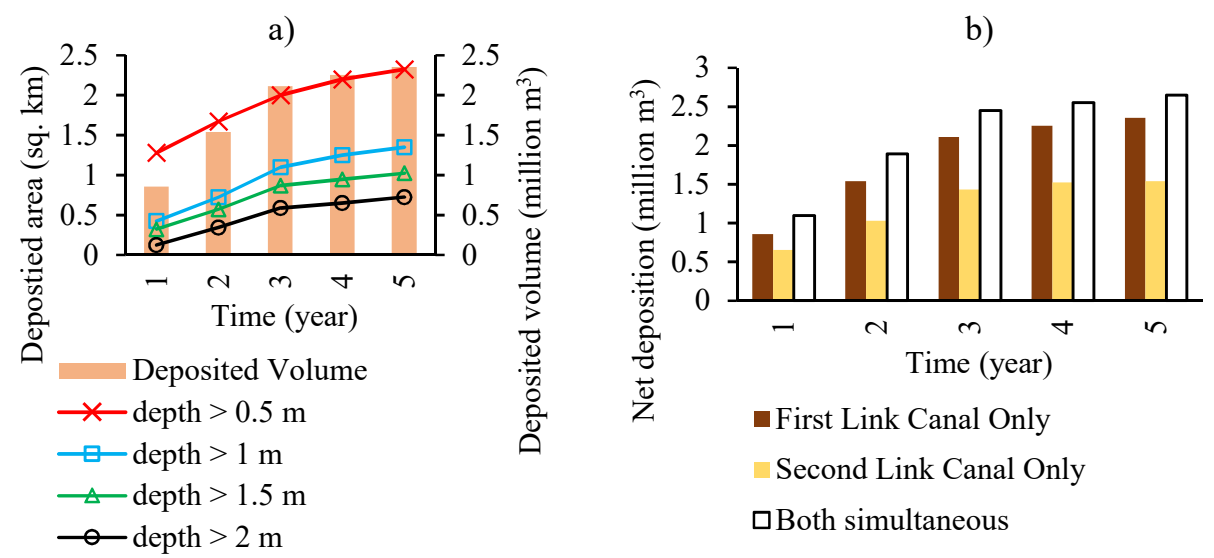

Fig. 7. Net predicted deposition volume for different depth for case 1 and net predicted deposition volume for three different cases. 


\section{Conclusions}

TBM involves temporary de-poldering and taking full advantages of natural tidal flow up and down. The application of the developed model has been tested in one of the actual cases of TBM operated beel. Firstly, the real scenario case was simulated and validated with available data. After that, the assessment of the TBM with one EC, another EC and simultaneous operated both ECs were performed. It is suggested to operate single EC in the tidal basin if the tidal equilibrium is fulfilled by opening size of that EC.

The developed model can be used to simulate to explore the best location of the EC. It can be used as a decision-making tool to assess the sediment transport, land heightening and ultimately the age of operation of TRM in a designated tidal basin for sustainable sediment management. It can also be used to assess the effectivenes of blending of engineering works (like dredging around EC, compartmentalization of tidal basin, channel improvement of tidal river etc.) along with natural tidal movement.

In the current study, the salinity has not been taken care. In the actual case of tidal movement, the brackish water coming from the sea has high salinity level. As already known, the sediment transport process and deposition pattern are totally different with saline water, there are many possibilities to carry out the experiments and numerical simulations considering salinity to better understand TBM process.

\section{Acknowledgment}

The research is supported by JST/JICA SATREPS program on disaster prevention/mitigation measures against floods and storm surges in Bangladesh (PI: Dr. H. Nakagawa).

\section{References}

1. A. M. Rezaie \& U. K. Naveram, Adv. River Sediment Res. 1363-1375 (2013)

2. M. Z. Rahman, M. S. Islam \& Z. H. Khan, International Conference on Recent Innovation in Civil Engineering for Sustainable Development 954-959 (2015)

3. Shampa \& M. I. M. Pramanik, Int. J. Sci. Technol. Res. 1, 1-6 (2012)

4. M. S. I. Ibne Amir, M. S. A. Khan, M. M. Kamal Khan, M. Golam Rasul \& F. Akram, Int. J. Civil, Archit. Struct. Constr. Eng. 7, 183-193 (2013)

5. IWM, Feasibility Study Detailed Engineering Design for long term Schedule of Drainage Problems in the Bhabodah Area (2010)

6. M. W. Ullah \& S. Mahmud, 6th International Conference on Flood Management 133-140 (2017)

7. A. Paul, B. Nath \& M. R. Abbas, Int. J. Geomatics Geosci. 4, 125-135 (2013)

8. R. Karim \& R. Mondal, Hydro. 5, 1-6 (2017)

9. M. B. Edrish, S. Yeasmin \& S. Rahman, 6th International Conference on Flood Management 141-149 (2017)

10. K. N. H. Haque, F. A. Chowdhury \& K. R. Khatun, Land and Disaster Management Strategies in Asia 189-208 (2015)

11. M. F. van Staveren, J. F. Warner \& M. S. A. Khan, Water Policy 19, 147-164 (2017)

12. A. K. Gain, D. Benson, R. Rahman, D. K. Datta \& J. J. Rouillard Environ. Sci. Policy 75, 111-120 (2017)

13. Kibria, Z. Tidal River Management (2011)

14. Asian Development Bank. Bangladesh: Khulna-Jessore Drainage Rehabilitation Project (2007)

15. M. Al, N. Naher, H. Azadi \& S. Van. Passel, Ecol. Indic. 85, 451-467 (2018) 
16. M. Mutahara, J. F. Warner, A. E. J. Wals, M. S. A. Khan \& P. Wester, Int. J. Water Resour. Dev. 1-21 (2017)

17. R. Talchabhadel, K. Ota, H. Nakagawa \& K. Kawaike, J. Japanese Soc. Civ. Eng. Ser B1 Hydraul. Eng. 74, 955-960 (2018)

18. R. Talchabhadel, H. Nakagawa, K. Kawaike \& N. Sahboun, 37th IAHR World Congress 478-487 (2017)

19. R. Talchabhadel, H. Nakagawa, K. Kawaike, M. Hashimoto \& N. Sahboun, J. Japanese Soc. Civ. Eng. Ser B1 Hydraul. Eng. 73, 781-786 (2017)

20. K. H. Kabir \& S. Aftab, Asian Dev. Policy Rev. 5, 70-80 (2017)

21. J. N. van Minnen, MSc. Thesis Wageningen University (2013)

22. W. W. Rubey, Am. J. Sci. 225, 325-338 (1933)

23. L. C. van Rijn, J. Hydraul. Eng. ASCE 110, 1494-1502 (1984)

24. Y. Iwagaki \& Y. Tsuchiya, Trans. JSCE 41, 1-21 (1956)

25. K. Kawaike, K. Inoue \& K. Toda, Hydrosoft 2000, Hydraul. Eng. Softw. VIII, 457-466 (2000)

26. K. Kawaike, K. Inoue \& K. Toda, Annu. J. Hydraul. Eng. JSCE 44, 461-466 (2000)

27. M. S. I. Ibne Amir, MSc. Thesis Bangladesh University of Engineering and Technology (2010)

28. Y. Ogawa \& K. Sawai, Adv. River Sediment Res. 1417-1424 (2013)

29. T. M. Hume \& C. Herdendorf, J. Coastal Research 9, 413-422 (1993)

30. M. P. O'Brien, J. Waterw. Harb. Div. WW1, 43-52 (1969)

31. M. A. Powell, R. J. Thieke \& A. J. Mehta, Ocean Dyn. 56, 295-307 (2006)

32. J. Van de Kreeke \& J. Haring, International Conference on Coastal Engineering, ASCE 2627-2639 (1980) 